Brit. J. industr. Med., 1950, 7, 82.

\title{
POSSIBLE LONG TERM EFFECTS OF EXPOSURE TO SULPHUR DIOXIDE
}

\author{
BY \\ A. ANDERSON \\ From the Anglo-Iranian Oil Co., Ltd., Abadan, South Persia
}

(RECEIVED FOR PUBLICATION JANUARY 3, 1950)

Sulphur dioxide is one of the oldest products of industry to which man has been exposed and its use under modern conditions is widespread. The effect of exposure to sulphur dioxide has attracted little attention, however, beyond studies of the immediate effects, and I have found only one controlled investigation into the long term effects (Kehoe, Willard, Kitzmiller, and Leblanc, 1932).

The immediate consequences of exposure to heavy concentrations are no concern of this paper, although at Abadan we are aware of the effects on the eye, the skin, and the lungs. They can be severe, but there has been no record of death due to exposure to sulphur dioxide in Abadan over the past five years.

The present investigation was stimulated by statements by labourers, supervisors, and others that in their view continued exposure to the fumes of sulphur dioxide must be a contributory cause, if not the cause, of tuberculosis, chronic bronchitis, and other chronic chest disease ; and the confusion in the medical literature with regard to the immediate effects of exposure to heavy concentrations and the long term effects of ordinary industrial exposure. For instance, Kehoe and others (1932), Johnstone (1948), and Sappington (1943) maintain that chronic chest disease from ordinary industrial exposure will not occur. On the other hand, Romanoff (1939) and Dowling (1937) have reported cases of asthma following the inhalation of sulphur dioxide. Admittedly the asthma occurred in patients with a manifest allergic diathesis and after fairly severe exposure, although accurate assessment of the exposure was sometimes difficult to obtain. Enquiries as to long term effects have been made of authorities in the United Kingdom, but as a rule the answers have been expressions of opinion, and it is admitted that there is little direct evidence. Many people are influenced by the obvious immediate results of exposure to heavy concentrations and feel that chronic effects must inevitably occur.

\section{Conditions at Abadan}

Oil refineries are large users of sulphur dioxide, and at Abadan there are two important processes in which it is used (1) the refining plant (R.P. Area), and (2) the special products plant (S.P. Area).

These plants are housed in steel frame buildings, open on all sides and roofed over for protection from sun and rain so that ventilation is unusually good and escape from any major catastrophe unusually easy. This form of construction is also desirable in a country where the shade temperature may rise to $123^{\circ} \mathrm{F}$. in summer and seldom falls below about $40^{\circ} \mathrm{F}$. in winter.

Theoretically, the sulphur dioxide at each plant is in a closed circuit, but no mechanical pump yet devised is completely leak-proof in operation, and other minor sources of leak exist. Recent estimations of the concentration of sulphur dioxide in the atmosphere at these plants have shown that figures between 0 and 25 p.p.m. are usual. Estimations taken during the years 1938-45, when maintenance of the plant was relatively low, sometimes showed figures varying between 60 and 100 p.p.m., and one sample, which was deliberately taken near a pump gland temporarily out of commission, showed 200 p.p.m. The commonly accepted maximum allowable concentration is 10 p.p.m.

\section{Method of Investigation}

In each area (R.P. and S.P.) two groups of workers were chosen. The contact groups consisted of men who were exposed to sulphur dioxide, and the control groups of men engaged in the same areas, but with no recorded exposure to sulphur dioxide. The climatic conditions were the same for each group, and they had the added statistical advantages of being all Iranian nationals and all subject to similar conditions as regards working hours, clothing, housing, wage scales, and nutritional status. The choice was left to the supervisor 
TABLE 1

Comparison of Groups by Age

\begin{tabular}{|c|c|c|c|c|c|c|}
\hline \multirow{2}{*}{\multicolumn{3}{|c|}{ Age Group (Years) }} & \multicolumn{2}{|c|}{ R.P. Area } & \multicolumn{2}{|c|}{ S.P. Area } \\
\hline & & & Contacts & Controls & Contacts & Controls \\
\hline \multicolumn{3}{|c|}{$\begin{array}{l}15 \\
20 \\
25 \\
30 \\
35 \\
40 \\
45 \\
50 \\
55 \\
60 \\
65 \\
70\end{array}$} & $\begin{array}{r}3 \\
5 \\
21 \\
11 \\
15 \\
19 \\
11 \\
8 \\
3 \\
1 \\
-\end{array}$ & $\begin{array}{r}10 \\
7 \\
8 \\
7 \\
16 \\
12 \\
12 \\
17 \\
9 \\
2 \\
-\end{array}$ & $\begin{array}{r}3 \\
2 \\
9 \\
7 \\
7 \\
5 \\
3 \\
= \\
= \\
= \\
-\end{array}$ & $\begin{array}{c}1 \\
8 \\
6 \\
6 \\
3 \\
3 \\
3 \\
2 \\
\frac{2}{1} \\
1\end{array}$ \\
\hline Total .. & . & .. & 97 & 100 & 36 & 35 \\
\hline $\begin{array}{l}\text { Mean .. } \\
\text { S.D. .. }\end{array}$ & $\begin{array}{l}. \\
\cdots\end{array}$ & $\begin{array}{l}\ldots \\
\ldots\end{array}$ & $\begin{array}{l}37 \cdot 60 \\
10 \cdot 10\end{array}$ & $\begin{array}{l}39.95 \\
11.85\end{array}$ & $\begin{array}{r}33 \cdot 05 \\
7 \cdot 57\end{array}$ & $\begin{array}{l}35 \cdot 50 \\
13 \cdot 20\end{array}$ \\
\hline \multicolumn{2}{|c|}{$\begin{array}{l}\text { Difference ... } \\
\text { S.E. of difference }\end{array}$} & $\begin{array}{l}\ldots \\
\cdots\end{array}$ & \multicolumn{2}{|c|}{$\begin{array}{l}2.35 \\
1.56\end{array}$} & \multicolumn{2}{|c|}{$\begin{array}{l}2 \cdot 45 \\
2 \cdot 56\end{array}$} \\
\hline
\end{tabular}

of each area and in fact almost all the exposed personnel were examined. The control groups were chosen by the supervisors from non-exposed personnel working in the areas concerned, and the working record of each man was consulted before the choice was made in order to eliminate the possibility of previous contact. These individual records are kept by the central labour office and are accurate.

A standard card was printed on which was recorded the results of clinical examination. In addition, the vital capacity was estimated and a radiograph of the chest obtained in each case. These results were recorded on the same card. All clinical examinations were carried out by one medical officer, except for the first 40 or so out of a total of 278 examinations successfully completed and recorded. All the vital capacities were estimated or supervised by one laboratory technician.

All the radiographs were examined and recorded by one person on the following standard system : (1) Shape of chest ; (2) apices ; (3) heart shadow ; (4) hilar areas; (5) general lung fields. By these means it was hoped to eliminate as far as possible differences arising from personal bias. In the radiographs and the vital capacity estimations it was not known whether the particular result being assessed was from an exposed or a non-exposed worker. In the clinical examinations, it was impossible to eliminate this bias. It was hoped to show whether the contact groups showed any deviation in health compared with the control groups.

\section{Analyses of Tabulated Results}

In each area (Table 1) the means differ by approximately the standard error of the difference between them. Thisestablished a further similarity between the groups. The recording of age in an illiterate population is notoriously dangerous, but the risk almost certainly applied equally throughout.

In each area (Table 2) the means differ by approximately the standard error of the difference between them, a further similarity between the groups.

The means (Table 3 ) are very close together, and must be accepted as a further point of similarity between the groups.

The vital capacity (Table 4) is as good a measure of respiratory function as any at our command. Maxwell (1948) states that " vital capacity is an index of respiratory function", and Davidson (1948) that it has " frequently been adopted as a test of physical fitness". Best and Taylor (1945) state that the vital capacity is reduced in many diseased conditions, especially those involving the respiratory and vascular systems. They quote emphysema as an example. The estimation of vital capacity has also come to be almost a standard procedure when assessing the disability of the silicotic. As the groups used in this examination were comparable by weight and age, the correction for stature which 
TABLE 2

COMPARISON OF Groups BY WeIGHT

\begin{tabular}{|c|c|c|c|c|c|c|c|}
\hline \multirow{2}{*}{\multicolumn{4}{|c|}{ Weight Group (lb.) }} & \multicolumn{2}{|c|}{ R.P. Area } & \multicolumn{2}{|c|}{ S.P. Area } \\
\hline & & & & Contacts & Controls & Contacts & Controls \\
\hline \multicolumn{4}{|c|}{$\begin{array}{r}90 \\
100 \\
110 \\
120 \\
130 \\
140 \\
150 \\
160 \\
170\end{array}$} & $\begin{array}{r}3 \\
13 \\
18 \\
32 \\
23 \\
7 \\
3 \\
3 \\
2\end{array}$ & $\begin{array}{r}3 \\
15 \\
20 \\
30 \\
18 \\
7 \\
6 \\
1\end{array}$ & $\begin{array}{r}2 \\
1 \\
12 \\
8 \\
7 \\
5 \\
\frac{2}{2}\end{array}$ & $\begin{array}{r}2 \\
7 \\
8 \\
8 \\
6 \\
5 \\
-1 \\
-\end{array}$ \\
\hline Total ... & .. & $\ldots$ & .. & 104 & 100 & 37 & 37 \\
\hline $\begin{array}{l}\text { Mean ... } \\
\text { S.D. .. }\end{array}$ & 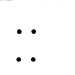 & $\begin{array}{l}\ldots \\
\ldots\end{array}$ & . & $\begin{array}{r}126 \cdot 44 \\
16 \cdot 13\end{array}$ & $\begin{array}{r}124 \cdot 60 \\
15 \cdot 22\end{array}$ & $\begin{array}{r}126 \cdot 35 \\
15 \cdot 79\end{array}$ & $\begin{array}{r}122 \cdot 84 \\
15 \cdot 99\end{array}$ \\
\hline \multicolumn{2}{|c|}{$\begin{array}{l}\text { Difference } \\
\text { S.E. of difference }\end{array}$} & $\begin{array}{l}\ldots \\
\ldots\end{array}$ & $\ddot{.}$ & \multicolumn{2}{|c|}{$\begin{array}{l}1.84 \\
2.19\end{array}$} & \multicolumn{2}{|c|}{$\begin{array}{l}3.51 \\
3.71\end{array}$} \\
\hline
\end{tabular}

is sometimes used was not thought to be necessary. It will be seen that the mean vital capacity is better in each contact group, and that the means in the S.P. Area differ approximately by as much as the standard error of difference between them. In the R.P. Area, however, the difference between the means is 3.89 times the standard error of the difference, a figure usually accepted as statistically significant. The reasons for this are unknown. It can be conjectured that deeper breathing occurs on exposure to an irritant gas, but this is offset by the fact that no significant difference was found in the
S.P. Area. It can only be stated that the contact group in the R.P. Area showed a significantly better mean vital capacity than the control group and that there is no evidence on this observation that their health was suffering as a result of exposure to sulphur dioxide. Considerable importance is attached to this finding, as it is the only time the vital capacity estimation has been used in this connexion, so far as is known, and it is felt that its simplicity of application and susceptibility to accurate measurement make it a valuable piece of evidence.

TABLE 3

Comparison of Groups by Blood Pressure

\begin{tabular}{|c|c|c|c|c|c|c|c|}
\hline \multirow{2}{*}{\multicolumn{4}{|c|}{ B.P. Group (Mm. Hg) }} & \multicolumn{2}{|c|}{ R.P. Area } & \multicolumn{2}{|c|}{ S.P. Area } \\
\hline & & & & Contacts & Controls & Contacts & Controls \\
\hline \multicolumn{4}{|c|}{$\begin{array}{l}100 \\
110 \\
120 \\
130 \\
140 \\
150 \\
160 \\
170 \\
180\end{array}$} & $\begin{array}{r}-7 \\
38 \\
27 \\
17 \\
8 \\
4 \\
1 \\
1\end{array}$ & $\begin{array}{r}3 \\
7 \\
31 \\
29 \\
11 \\
8 \\
4 \\
2 \\
1\end{array}$ & $\begin{array}{r}-4 \\
20 \\
7 \\
4 \\
- \\
-\end{array}$ & $\begin{array}{r}7 \\
15 \\
11 \\
3 \\
- \\
-\end{array}$ \\
\hline Total & . & & . & 103 & 96 & 36 & 37 \\
\hline $\begin{array}{l}\text { Mean } \\
\text { S.D. }\end{array}$ & $\begin{array}{l}\cdots \\
\cdots\end{array}$ & . & $\begin{array}{l}\ldots \\
\ldots\end{array}$ & $\begin{array}{r}135 \cdot 19 \\
13.65\end{array}$ & $\begin{array}{r}134 \cdot 79 \\
15 \cdot 20\end{array}$ & $\begin{array}{r}129 \cdot 72 \\
12 \cdot 36\end{array}$ & $\begin{array}{r}129 \cdot 32 \\
12 \cdot 63\end{array}$ \\
\hline \multicolumn{2}{|c|}{$\begin{array}{l}\text { Difference } \\
\text { S.E. of difference }\end{array}$} & & $\ddot{x}$ & \multicolumn{2}{|c|}{$\begin{array}{l}0 \cdot 40 \\
2 \cdot 05\end{array}$} & \multicolumn{2}{|c|}{$\begin{array}{l}0.40 \\
2.92\end{array}$} \\
\hline
\end{tabular}


TABLE 4

Comparison of Groups by Vital Capacity

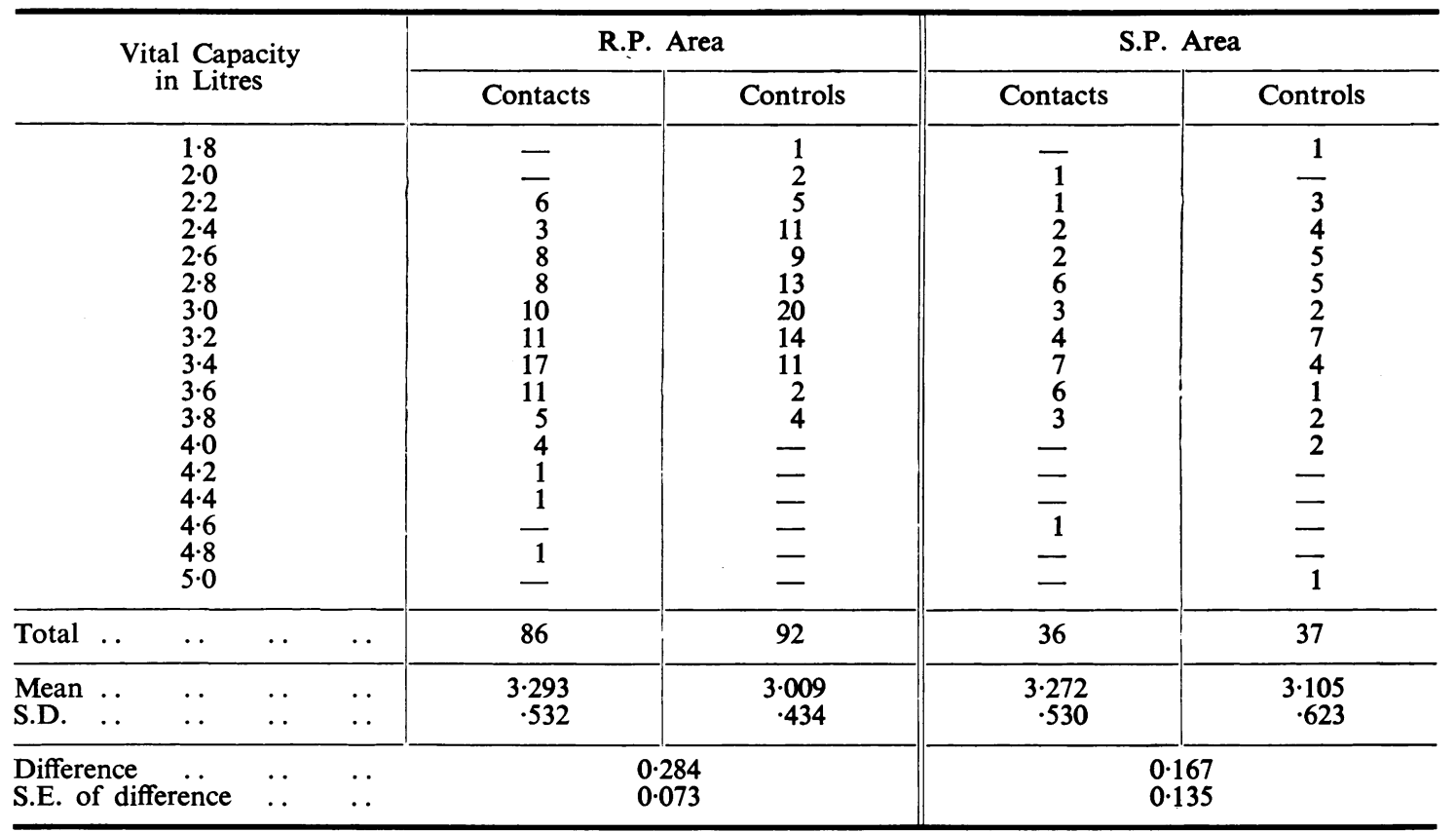

Having been aware of the likelihood of inconsistency in the interpretation of radiographs for some time, I was particularly interested in the findings of Birkelo, Chamberlain, Phelps, Schools, Zacks, and Yerushalmy (1947) that the opinions of different observers on the same film were often at variance and that even the same observer would give different opinions on the same radiograph on different occasions. This phenomenon has been further examined by Fletcher and Oldham (1949) with particular reference to coal miner's pneumoconiosis. Therefore, I read all the $x$-ray films myself, recording the results in the manner noted above. By this means the differences between observers were eliminated, and I attempted to curb the effects of my own mood and differing outlook over a period of 18 months by reading the films in batches of 30 to 40 .

No cases of active tuberculosis were found. This was surprising, as the incidence in Abadan is roughly twice that of the United Kingdom. The cases with quiescent Assmann's foci were subjected to full investigation in hospital, and the 20 cases designated " full investigation negative" were admitted because of other suspicious areas, usually in the region of the apex of the lower lobe. It will also be noted that the abnormal findings were distributed fairly evenly throughout the four groups.

TABLE 5

Comparison of Groups by Radiographic Findings

\begin{tabular}{|c|c|c|c|c|}
\hline \multirow{2}{*}{ Abnormality } & \multicolumn{2}{|c|}{ R.P. Area } & \multicolumn{2}{|c|}{ S.P. Area } \\
\hline & Contacts & Controls & Contacts & Controls \\
\hline $\begin{array}{l}\text { Calcified hilar areas ... } \\
\text { Assmann's focus (quiescent).. } \\
\text { Calcified extra hilar areas .. } \\
\text { Full investigation negative } \\
\text { Old pleurisy } \ldots \\
\begin{array}{l}\text {.. } \\
\text {. }\end{array}\end{array}$ & $\begin{array}{r}12 \\
4 \\
8 \\
11 \\
2\end{array}$ & $\begin{array}{r}15 \\
2 \\
10 \\
2 \\
4\end{array}$ & $\begin{array}{l}4 \\
\overline{-} \\
1\end{array}$ & $\begin{array}{l}3 \\
4 \\
4 \\
1\end{array}$ \\
\hline $\begin{array}{llll}\text { Total } \ldots & \ldots & \ldots & \ldots\end{array}$ & 37 & 33 & 8 & 12 \\
\hline
\end{tabular}


Odds and ends came to light of course. For example, several cases of syphilitic aortitis were discovered and treated, and one or two cases of amoebic hepatitis.

\section{Length of Exposure to Sulphur Dioxide}

In 101 subjects in the R.P. Area the exposure time was ascertained. Forty-five had been exposed from 1 to 4 years ; 35 from 5 to 14 years ; 21 from 16 to 19 years. The mean exposure time was $8 \cdot 15$ years. The S.P. Group, 37 in all, had a mean exposure time of 2.91 years due to the fact that the plant had been commissioned as recently as 1943 .

\section{Acclimatization Time}

As a matter of interest each man in the contact groups was asked how long he thought he had taken to become accustomed to the effects of sulphur dioxide in his working atmosphere. The replies were expressions of opinion only, but are nevertheless interesting.

TABLE 6

Stated Acclimatization Time

\begin{tabular}{ll|c|c}
\hline & & R.P. Area & S.P. Area \\
\hline 1-6 months & $\ldots$ & $67 \%$ & $92 \%$ \\
6-12 months & $\ldots$ & $16 \%$ & $8 \%$ \\
12-24 months &. & $15 \%$ & - \\
Over 24 months &. & $2 \%$ & - \\
\hline
\end{tabular}

"Acclimatization" is a word used frequently in Abadan with reference to hot weather conditions, and it was used as freely in Services medical circles during the recent war. The assessment of acclimatization is difficult, and not susceptible to measurement, but for some reason the S.P. workers felt that they became accustomed much more rapidly than did the R.P. workers. (It should be remembered that each clinical examination was an individual incident, so that collusion is unlikely.)

\section{Summary}

Workers exposed to daily concentrations of sulphur dioxide for periods of time varying from 1 to 19 years were examined. Special attention was paid to age, weight, blood pressure, vital capacity, and radiography of the chest. The daily concentration of sulphur dioxide varied between 0 and 25 p.p.m. Occasionally, figures of 100 p.p.m. were recorded.

Workers not exposed to sulphur dioxide but otherwise subject to similar working conditions and to similar living conditions were also examined, special attention being paid to the same details of examination.

No evidence of adverse effects on health could be found.

I wish to thank A. C. Turner, Esq., O.B.E., F.R.C.S., Chief Medical Officer to the Anglo-Iranian Oil Co., Ltd., in Iran, for permission to publish this paper. Many members of the works management, too numerous to mention, rendered invaluable assistance. I wish specifically to thank Dr. M. A. Khorram, who examined most of the cases clinically, Mr. J. Q. Gray, who performed or supervised the vital capacity estimations, and Mrs. T. L. Stephens, who did the laborious recording. Finally, I am indebted to 278 Persian workmen without whose cooperation the investigation would have been impossible.

\section{REFERENCES}

Best, C. H., and Taylor, N. B. (1945). “"The Physiological Basis of Medical Practice." Baillière, Tindall and Cox. London. P. 309.

Birkelo, C. C. Chamberlain, W. E., Phelps, P. S., Schools, P. E., Zacks, D., and Yerushalmy, J. (1947). J. Amer. med. Ass., 133, 359 .

Davidson, M. (1948). " Practical Manual of Diseases of the Chest." Oxford University Press, London. P. 17.

Dowling, H. F. (1937). Med. Ann. Distr. Columbia, 6, 299.

Fletcher, C. M., and Oldham, P. D. (1949). British Journal of Industrial Medicine, 6,168 .

Johnstone, R. T. (1948), "Occupational Medicine and Industrial Hygiene." Henry Kimpton. London. Pp. 182 and 404.

Kehoe, R. A., Willard, F. M., Kitzmiller, K., and Le Blanc, T. J. (1932).' J. industr. Hyg., 14, 159.

Maxwell, J. (1948). "Introduction to Diseases of the Chest." Hodder and Stoughton. London. P. 16.

Romanoff, A. (1939). J. Allergy, 10, 166.
Sappington. C. O. (1943). "Essentials of Industrial Health." J. B. Lippincott Co. New York. P. 495. 